DR. VÍ́CTOR ROLO (Orcid ID : 0000-0001-5854-9512)

Article type : Research article

Co-ordinating Editor : Alicia Teresa Rosario Acosta

Coordinating Editor: Prof. Alicia Teresa Rosario Acosta

\title{
Determinants of canopy gap characteristics in rehabilitating coastal dune forests
}

Victor Rolo, Pieter I. Olivier and Rudi J. van Aarde

${ }^{1}$ Conservation Ecology Research Unit, University of Pretoria, Pretoria, South Africa

${ }^{2}$ Current address: Forest Research Group, Indehesa, University of Extremadura, Plasencia, Spain

Rolo V. (Corresponding author, victorroloromero@gmail.com) $)^{1,2}$

Olivier P. I. ${ }^{1}$

van Aarde R. J. ${ }^{1}$

Running head: Canopy gaps in dune forest

\section{Abstract \\ Questions}

What drives canopy gap formation in regenerating coastal dune forest? Does canopy gap size-frequency distribution differ between new- and old-growth forests? Can canopy gaps divert regenerating trajectories?

This article has been accepted for publication and undergone full peer review but has not been through the copyediting, typesetting, pagination and proofreading process, which may lead to differences between this version and the Version of Record. Please cite this article as doi: $10.1111 /$ avsc. 12380

This article is protected by copyright. All rights reserved. 
Location

Rehabilitating coastal dune forest in KwaZulu-Natal, South Africa

Methods

We mapped canopy gaps in regenerating dune forests patches of varying ages, that develop after the seeding of the pioneer Vachellia kosiensis, and a reference forest by means of unsupervised classification of multi-spectral satellite images. We tested if gap formation can be explained by abiotic (exposure to winds) and/or biotic (tree density at early stages) variables. We calculated the scaling exponent of a power-law model to quantify if gap size-frequency differed between new- and old-growth forests. Finally, we measured canopy openness, tree height and number of stems to validate canopy gap classification and assess the consequences of canopy gaps on regenerating trajectories.

Results

Exposure to winds and tree density at early stages were both significant predictors of gap presence. Gaps were more likely to be present along dune ridges and areas with low tree density than valleys and areas with high tree density at early stages. Large gaps were common in both new- and old-growth forests. The scaling exponent was positively related to regeneration age, indicating a reduction in gap size as the forest aged. Areas with open canopies had shorter individual trees that were more likely to be multi-stemmed than areas with closed canopies.

\section{Conclusion}

Canopy gaps are an important component of new, and old-growth coastal dune forests dynamics. Although gaps are filled during forest development, changes in individual life-history strategies and morphology may alter regeneration trajectories. However, because their effect is partly controlled by the exposure to winds and tree density at early stages it can also be manipulated by management to ensure nucleation, which could accelerate forest recovery. 
Keywords: random forest classification; SPOT6; size-frequency distribution; hierarchical Bayesian models; multi-stemming; canopy openness.

\section{Introduction}

Canopy gaps are important determinants of tree species diversity in forest worldwide (Schnitzer \& Carson 2001; Baraloto et al. 2012). Because of their varying size, they provide for a range of environmental conditions, which allow species with different life-histories to regenerate and co-occur (Brokaw 1985). Shade-intolerant species often fill large gaps, whereas shade-tolerant species fill small gaps (Denslow 1980; Fahey \& Puettmann 2007). The opening of canopy gaps, therefore, is sometimes used to assist forest restoration - for example facilitating the replacement of commercial plantations by natural forest (Forbes et al. 2016) or to restore degraded forest invaded by exotic species (Forbes 2017). However, if canopy gaps are too small, or if large gaps dominate the forest, it can have neutral or negative effects on species diversity (Vleut et al. 2013; Pasanen et al. 2016), and potentially affect regeneration trajectories of rehabilitating forest (Grainger \& van Aarde 2013).

The formation of natural gaps may be particularly commonplace in restoration initiatives that relies on the seeding of fast-growing species and results in the establishment of high density stands. High densities at young stages can lead to high tree mortality due to density-dependent processes (Larson et al. 2015). Competition for light in young regenerating stands can force trees to be structurally imbalanced (i.e. promoting height at the expense of structural support), which can reduce their resistance to abiotic disturbances and thus increase tree mortality (King et al. 2006). For instance, an increased exposure to wind, or where local conditions magnify wind effects, may promote the opening of larger canopy gaps (Goulamoussène et al. 2017). In addition, topographic and climatic factors, species composition before gap formation and vegetation structure can also affect canopy gaps (Liao et al. 2015). However, it remains unclear how the presence of gaps affects regenerating trajectories of young high density forest in the absence of any managerial intervention in passive restoration projects.

Canopy gaps may have a profound effect on regeneration trajectories of young forest by changing species composition and causing shifts in individual species morphology and life-history strategies as compared to an old-growth forest. For instance, gap formation could promote the presence of multi-stemmed individuals (Dietze $\&$ Clark 2008) by causing an increase in the abundance of species whose regenerating strategies rely on multi-stemming (Dietze \& Clark 2008) or because of the ability of some species to resprout with partly damaged stems. Resprouters with partly damaged stems can quickly recover after a disturbance (Nzunda et al. 2008) - they therefore have been used as a 'shortcut' to restore the canopy (Dietze \& Clark 2008). However, multi-stemmed individuals may not reach their potential height (i.e. trade-off multi-stemming-maximum height) because the potential for vertical growth may be hindered by the allocation of resources to multiple stems (Bond \& Midgley 2003). If an increase in the abundance of multi-stemmed individuals reduce plant height, then canopy recovery could be impaired in the long-term, which could potentially cascade to other trophic levels (Lindenmayer et al. 2012). Large differences in the size-frequency distribution of gaps between young and old growth forest may, therefore, be indicative of potentially divergent regeneration trajectories from the endpoint. 
To fully understand the potential effect of canopy gap presence on regeneration trajectories, information at larger spatial scales is needed (Asner et al. 2013). Information from field plots are insufficient to characterize size-frequency distributions of gaps at larger scales, as they usually only capture a small spatial extent (Asner et al. 2013). For instance, using field plots may not be possible to assess if large canopy gaps occur at high frequencies at the regional scale, overlooking synchronised episodes of tree mortality. To overcome this limitation, satellite images are widely used to study gap dynamics at regional levels (Garbarino et al. 2012; Malahlela et al. 2014; Pinagé et al. 2016). Satellite images offer the possibility of sampling canopy level processes across large areas, which could provide new insights on previous findings based on field studies (Chambers et al. 2007). High resolution satellite images can also provide regional measures of gap size-frequencies and, therefore, help unravel the causes of gap size variation and the role of biotic and abiotic factors in canopy gap formation.

In this study, we aim to assess characteristics of canopy gap in regenerating coastal dune forest that develops after rehabilitation. We determined gap size-frequency distribution and assessed the effect of exposure to winds and tree density at early stages on canopy gap formation. In the rehabilitating forest, the pioneer species Vachellia kosiensis (formerly Acacia karroo) was seeded to kick-start succession (van Aarde et al. 1996), but at the age of 20 years this species become senescent, affecting the species composition and function of rehabilitating forest (Grainger \& van Aarde 2013; Rolo et al. 2016). This questions the facilitative role attributed to pioneer plantations that are used to restore tropical forest (Lamb et al. 2005). Specifically, we aim to answer: i) Is gap presence mediated by exposure to winds and/or tree density at early stages? ii) Does gap size-frequency distribution differ between rehabilitating and old-growth dune forest? If so, iii) Is gap size-frequency distribution related to age since rehabilitation? iv) Does gap presence increase the number of multi-stemmed individuals? We expect that the disturbance regime of rehabilitating forest that uses fast-growing species is mediated by exposure to wind and characterized by the presence of large canopy gaps which can potentially affect the recovery of regenerating species. We expect that the frequency of large canopy gaps will be higher in older than younger rehabilitating forests. Because regenerating forests are dominated by the pioneer Vachellia kosiensis, we also expect a higher frequency of canopy gaps in rehabilitating than old-growth dune forest. We argue that the understanding of gap formation and the subsequent replacement of species is of major importance to predict regenerating trajectories in restoration initiatives that use fast-growing species.

\section{Material and Methods}

Study area

Our study sites included a set of regenerating forests on mined coastal sand dunes and an undisturbed, old-growth coastal dune forest (Sokhulu forest, $28^{\circ} 27^{\prime} \mathrm{S}, 32^{\circ} 25^{\prime} \mathrm{E}$; hereafter old-growth) in KwaZulu-Natal, South Africa (Appendix S1). The regenerating (new-growth forest) forests stretched approximately $20 \mathrm{~km}$ north of Richards Bay $\left(28^{\circ} 43^{\prime} \mathrm{S}, 32^{\circ} 12^{\prime} \mathrm{E}\right)$ and formed part of the Indian Ocean Coastal Belt (IOCB) forests of southern Africa (Mucina et al. 2006). The IOCB covers a narrow strip (less than $\sim 35 \mathrm{~km}$ wide) along $800 \mathrm{~km}$ of the eastern seaboard of South Africa and represents the southernmost range of East African Coastal Forest that extends northwards as far as 
southern Somalia (Burgess \& Clarke 2000). The climate of the study area is humid and sub-tropical (van Aarde et al. 2014). Long term mean annual rainfall since rehabilitation (1976-2015) was $1336 \pm$ $117 \mathrm{~mm}_{\text {year }}{ }^{-1}$.

The unmined old-growth forest included in this study was situated about $14 \mathrm{~km}$ northwards of the rehabilitating sites. This forest was $\sim 500$ ha in area and formed part of the dune forest in the Mapelane Nature Reserve ( $\sim 1500$ ha), which forms part of the iSimangaliso Wetland Park, a RAMSAR World Heritage site. This old-growth forest was the closest relatively large patch of undisturbed forest to the mining lease area.

The mining process started in 1976 and required the removal of all vegetation on the dunes (van Aarde et al. 1996). After mining the sand tailings were reshaped into dunes and covered with the pre-mined harvested topsoil. These sites were seeded with a cover crop of annuals and grasses enriched with the seeds of the pioneer tree species Vachellia kosiensis (P.P.Sw. ex Coates Palgr.) Kyal. \& Boatwr. Afterwards the vegetation was allowed to develop on its own accord (van Aarde et al. 1996). This resulted in the establishment of a sequence of known-aged sites. Individuals of $V$. kosiensis have been shown to be senescent by about 20 years old (Gourlay et al. 1996). After this age, dead individuals fall and canopy gaps appear (Grainger \& van Aarde 2013), which could act as an environmental filter for the regenerating vegetation (Rolo et al. 2016).

Field data collection

Six sites (five new-growth forest and the old-growth forest used as the reference) were sampled in 2015. The age of new-growth forest sites in 2015 was 23, 27, 31, 35 and 38 years. We only sampled sites older than 20 years to ensure that individuals of Vachelia kosiensis had gone senescent. New-growth forests covered an area of approximately 400 ha (78.7 $\pm 19.5 \mathrm{ha} / \mathrm{stand})$. Woody plant surveys were conducted in 15 randomly located quadrats of $16 \times 16 \mathrm{~m}$ for each site. In every quadrat all woody plants (hereafter trees for simplicity) with DBH greater than one $\mathrm{cm}$ were recorded: multi-stemming (number of stems originating at the base of the individual) and maximum height of the largest stem were also recorded as a categorical factor in two meters steps.

Canopy openness (sensu Jennings et al. 1999) was estimated in each site by taking five hemispherical photographs at three different exposure settings in each of the 15 quadrats. We used a Canon 6D camera fitted with a Canon 8-14mm lens (Canon Inc. Tokyo, Japan) and mounted on a $1 \mathrm{~m}$ tripod (Benro, KB1, USA). We followed a similar approach to that described by Pfeifer et al (2012). Canopy openness was calculated for each hemispherical photograph by means of Gap Light Analyzer (GLA) software (Frazer et al., 1999) and averaged for each quadrat.

Mapping forest gaps

One SPOT-6 scene covering the studied sites was provided by the South African National Space Agency (SANSA) (acquired 15th August 2015). The SPOT-6 scene contained two images: a $6 \mathrm{~m}$ multispectral image with blue, green, red and near-infrared (NIR) bands and a 1.5 panchromatic image. SANSA provided the SPOT-6 scene orthorectified and projected to the UTM zone 36S. We use 
ArcMap 10.4 apparent reflectance function to perform a radiometric correction of the SPOT-6 scene by converting the digital numbers to top of atmospheric reflectance.

To identify canopy gaps, we used an unsupervised pixel classification by means of a random forest algorithm. This classification was based on a stacked image of the normalized digital vegetation index (NDVI) and two NDVI textural measures (i.e. mean and standard deviation) generated with a kernel of $3 \times 3$ pixels. Textural analysis is a reliable method to detect canopy structural heterogeneity (Bastin et al. 2014). As oppose to non-processed remote sensing image, band ratios such as NDVI limit the influence of shadows and illumination differences in images with high presence of shadows, such as gap and non-gap areas (Asner \& Warner 2003). Moreover, in our study sites canopy openness and NDVI values were negatively related $\left(p<0.001, r^{2}=0.62\right)$, indicating that quadrats with low values of NDVI are likely to have gaps in the canopy.

To train the random forest algorithm we classified quadrats based on canopy openness values as gap or non-gap. Defining a threshold value to distinguish between gap and non-gap areas is still a matter of debate. For instance, earlier classifications based on tree height define gaps as openings in the forest canopy extending down to a previously defined fixed value (e.g. $\leq 2 \mathrm{~m}$; Brokaw 1982), whereas more recent procedures consider threshold values as a continuum and define gaps along the whole vertical profile (e.g. in steps of $1 \mathrm{~m}$; Asner et al. 2013). To identify a threshold value for canopy openness in our study, we adapted the probabilistic approach proposed by Goulamoussène et al. (2017). This approach is based on the assumption that forest canopy openness can be modelled as a function of two ecological states: the natural variation of canopy openness and the presence of forest gaps. The concurrent distribution of both ecological states depicts a mixture of two normal distributions, the one for canopy openness with a higher mean value (Appendix S2). We defined the threshold between both states as the canopy openness value below which $99.9 \%$ of the natural variation on canopy openness can be found. As a result, quadrats having a canopy openness value higher than $45 \%$ were defined as gaps. We then extracted pixel values of the stacked image in gap and non-gap areas to perform the unsupervised classification. The classification produced a polygon vector map depicting each canopy gap detected in the original image. We found that $83 \%$ of canopy gaps reported in an independent dataset of 40 field observation of gaps in the same study sites (CERU unpublished data) were correctly classified as gaps. In additional, we visited 30 points (the fifteen lowest and highest NDVI values) to evaluate visually the presence or absence of gaps. We found that $87 \%$ of the points with the lowest NDVI values had canopy gaps and $73 \%$ of the points with highest NDVI values lacked canopy gaps. These results indicate that, on average, $80 \%$ of the points were correctly classified. Finally, we measured the number of pixels of each gap as a proxy of gap size.

\section{Environmental metrics}

Two environmental metrics were generated, one that characterized the biotic and one the abiotic environment of the study sites. For the abiotic attribute, we computed a topographic exposure index (TOPEX). This metric quantifies the degree of exposure to wind by considering the relative heights and distances of the horizon surrounding a point (Chapman 2000). We chose this abiotic metric because areas exposed to wind are prone to have canopy gaps (Goulamoussène et al. 2017) and coastal winds are an important determinant of canopy gap presence in coastal dune 
forests (Nzunda et al. 2007). To calculate TOPEX values, we followed the approach proposed by (Mikita \& Balogh 2015) using a 25 m resolution digital elevation model (DEM) provided by the National Geo-spatial Information of South Africa (www.ngi.gov.za). This DEM was derived from stereo digital imagery and has an accuracy of $3 \mathrm{~m}$ at $95 \%$ confidence interval. Topographic exposure values were calculated as:

$$
\text { TOPEX }=\sum_{i=1}^{n} \text { exposure to } \text { wind }_{i} * \text { wind frequency }
$$

, where i represents one of the $n$ cardinal directions $(n=8)$, exposure to wind hillside values computed in ArcMap 10.4 and wind frequency the proportion of winds that blow for each cardinal direction. Wind frequencies were obtained from the meteorological station in Richards Bay. High values of TOPEX indicate a higher exposure to wind.

For the biotic attribute, we used NDVI values at ten years after the rehabilitation was initiated at each stand. We assumed that NDVI values at ten years since seeding could be used as a proxy of tree density at early stages because before this threshold self-thinning processes are unlikely and the forest canopy may still be intact. Indeed, after ten years since seeding there is a steep increase in yield in $V$. kosiensis plantations (Barnes et al. 1996) which, therefore, may represent the end of the juvenile development phase (Pretzsch 2009). NDVI images at ten years since seeding were generated in Google Earth Engine, a cloud platform for earth observation data analysis that combines a public data catalogue with a large-scale computational facility. We used scenes from the USGS Landsat 5 collection that were orthorectified and top-of-atmosphere reflectance corrected (i.e. LANDSAT/LT5_L1T_TOA_FMASK collection). As a result, $30 \mathrm{~m}$ resolution NDVI images were generated for the years 1987, 1990, 1994, 1998 and 2001 (Appendix S3), ten years after the establishment of each new-growth forest.

\section{Data analysis}

To assess the influence of TOPEX and tree density at early stages (estimated through NDVI images at ten years since establishment) on the probability of gap presence, we fit a Bayesian model assuming that gap presence/absence data followed a Bernoulli distribution with TOPEX and tree density at early stages as linear predictors of the probability of success. To select non-gap areas, we randomly paired each gap with a surrounding non-gap point that had high NDVI value. As the resolution of the NDVI image was $30 \mathrm{~m}$, we only chose gaps whose size was $\geq 900 \mathrm{~m}^{2}$ for this analysis. Both TOPEX and tree density at early stages were standardized to have a mean of zero and a standard deviation of one. We excluded the old-growth forest in this analysis because tree density at early stages has no biological meaning for this type of forest.

To determine if the size frequency distribution was different among sites, we used a discrete power law probability density function (i.e. discrete Pareto distribution; Asner et al. 2013). According to this distribution, the probability that gap size take the integer value of $k$ is: 


$$
f(k)=\frac{k^{-\lambda}}{\zeta(\lambda)}
$$

where the denominator $(\zeta)$ is the Riemann zeta function and $\lambda$ is the scaling parameter. The scaling parameter describes the negative slope that takes size-frequencies when plotted on a logarithmic scale. Large values indicates the dominance of small gaps, whereas values close to one indicate an increased frequency of large gaps (Asner et al. 2013).

Parameter values were estimated using a hierarchical Bayes model. We modeled gap size as a discrete Pareto distribution allowing the scaling parameter $(\lambda)$ to vary among sites in a varying-intercept model with normally distributed group-level errors. As the scaling parameter can only take on values higher than one, we constrained $\lambda$ using:

$$
\lambda=1+e^{\alpha}
$$

To estimate parameters posterior distributions we built a Metropolis-Hastings ( $\mathrm{MH}$ ) algorithm following Hobbs and Hooten (2015). We used this algorithm because the discrete Pareto distribution is not included in typical Bayes software (e.g. OpenBUGS). We considered that sites had significantly different gap size distributions when parameters $95 \%$ credible intervals did not overlap.

We used a hierarchical Bayes model to assess the potential consequences of gap presence on regenerating trajectories. Particularly, we assessed if gap presence increased the probability of finding multi-stemmed individuals which, in turn, will reduce its maximum height. For this analysis we used field data where canopy openness and multi-stemming was measured. We classified each individual into two binary variables based on whether it had several stems or not and if it was higher than two meters or not. We modelled the number of multi-stemmed individuals per quadrat as a random variable drawn from a binomial distribution with values of canopy openness as a linear predictor of the probability of being multi-stemmed. We then used the calculated probability of being multi-stemmed as a linear predictor of the probability of being higher than two meters, accounting that the number of individuals higher than two meters was also drawn from a binomial distribution. Additionally, we tested in separate models if the probability of finding multi-stemmed or tall individuals differed among stands.

In all models we used proper, non-informative priors. For the gap presence probability and multi-stemmed models we computed posterior distribution of parameters using Markov chain Monte Carlo (MCMC) implemented in OpenBUGS (v3.2.3) using the R package R2WinBUGS (Sturtz et al. 2005). We generated three chains of 10000 iterations after a burn-in of 1000 for each model. We assessed convergence using the Gelman-Rubin statistic where values $<1.1$ indicated convergence (Hobbs \& Hooten 2015). All analyses were carried out in the R statistical environment (v3.4.0, R Core Team 2017). 


\section{Results}

Environmental controls of gap presence

Both environmental metrics were significant predictors of the probability of gap presence, but showed contrasting effects. TOPEX showed a positive effect on the probability of gap presence. We observed that an increase by one standard deviation of TOPEX, while NDVI values keeping constant, increased the probability of gap presence by $3 \%$. On the other hand, tree density at early stages (NDVI at ten years since establishment) had a negative effect on the probability of gap presence. An increase in tree density at early stages by one standard deviation led to a 90\% decrease in the probability of gap presence, which indicate that points with high values of tree density at ten years since rehabilitation were likely to have high values of tree density in 2015. In other words, areas where $V$. kosiensis occurred at high densities during the early stages of regeneration, were less likely to have gaps as the forests aged.

Size frequency distribution of gaps

Gap size metrics differed among the six forest sites. Gap cover and density were low in old, but high in young regenerating sites (Table 1). Gap cover were nearly three times ( $30 \%$ ) higher in the younger than older forests ( $\sim 10 \%)$. The old growth forest and the oldest new growth forest had similar values of gap cover ( $\sim 10 \%)$ and density $\left(2.5\right.$ gaps $\left.^{-1}{ }^{-1}\right)$. The biggest gap was located in the second oldest ( 35 years) regenerating forest ( $7 \mathrm{ha}$ ) and the smallest in the oldest (38 years) regenerating forest. The oldest regenerating site also had the lowest average gap size (Table 1 ). Despite these differences in descriptive statistics, power-law exponents ( $\lambda$-values) were similar across sites. We found that credible intervals of $\lambda$-values partly overlapped among sites. However, there was a significant relationship between $\lambda$-values and time since rehabilitation (Fig. 1 ). As the time since rehabilitation increased, $\lambda$-values significantly increased $(p=0.019)$, which indicate that the frequency of large gaps were higher in younger sites.

Consequences of gap presence on regenerating vegetation

Gap presence influenced plant life-history and morphology. Canopy openness was positively related to the presence of multi-stemmed plants, which in turn, was negatively related to the presence of individuals higher than $2 \mathrm{~m}$ (Fig. 2). This indicates that canopy gaps could trigger a trade-off between multi-stemming and maximum plant height. As the probability of multi-stemmed individuals increases, the maximum plant height of the individual decreases. The probability of finding a higher proportion of multi-stemmed individuals or individuals higher than $2 \mathrm{~m}$, was non-significant in the reference forest. However, all regenerating sites had a higher probability of finding multi-stemmed individuals and lower probability of finding individuals higher than $2 \mathrm{~m}$ than in the reference forest (Fig. 3). Only the oldest regenerating forest seemed to have a similar probability of finding individuals higher than $2 \mathrm{~m}$ than in the reference forest (i.e. partly overlaps zero), but the $95 \%$ credible interval was $(-0.159,-0.039)$ indicating that it was significantly different from zero. 


\section{Discussion}

Our results support the expectation that high-density stands resulting from the seeding of fast-growing species undergo a gap-phase with important consequences on regeneration trajectories. This finding is supported by the higher presence of multi-stemmed individuals and lower plant height in rehabilitating stands than in the reference forest. Despite large gaps occurred at a similar frequency in both young and old-growth forest, the linear relationship between power-law exponent values and age since rehabilitation suggest a divergent trajectory of size-frequency distribution of gaps from the endpoint.

A power-law exponent value of $\sim 2.0$ has been suggested as a threshold between sites dominated by large $(\lambda$-values $<2.0)$ or small $(\lambda$-values $>2.0)$ gaps (Asner et al. 2013$)$. We observed that $\lambda$-values ranged between 1.38 and 1.48 , confirming the prevalence of large gaps. However, we observed that all sites in the rehabilitating forest underwent a phase of generalized low NDVI values in the first years since establishment (Appendix S2). This pattern suggests that the disturbance regime in rehabilitating forest has the potential to reset regenerating trajectories at the site level. As a result, $\lambda$-values varied as the rehabilitated forest age, reaching a minimum at the lowest values of canopy cover following a recovery as the gaps are filled. In the old-growth forest, we observed that large gaps followed dune ridges, whereas in dune slacks large gaps were less frequent. This pattern was consistent across time, suggesting that this spatial distribution of gaps could promote environmental heterogeneity and drive species diversity in dune forests.

The pervasive effect of winds in coastal dune forest (Nzunda et al. 2007) agrees with the high frequency of large gaps (i.e. low power-law exponent values) found across the studied sites. This would be in agreement with the positive relationship found between higher probability of canopy gap formation and the topographic exposure index. Contrary to our expectations, the probability of canopy gap formation was negatively related to tree density at early stages (i.e. NDVI values at ten years following rehabilitation). Given that high densities at early stages has been shown to increase mortality by density-dependent processes (Larson et al. 2015), we expected a positive relationship between tree density and probability of gap presence. However, in our study this likely density-dependent process was not related to higher probability of gap presence. One explanation of this lack of relationship could be that the usefulness of using NDVI values at ten years following rehabilitation as a proxy of early tree density was limited. The low resolution of LANDSAT images may not be suitable to capture processes that occur at the local scale such as density-dependent mortality. Alternatively, this result may be also confound by the effect of topographical position, and therefore wind exposure, on canopy gap formation (Goulamoussène et al. 2017). Canopy gaps are less likely to be formed in dune slacks (Nzunda et al. 2007), thus these areas could keep high tree density through time. Yet, low tree density values would be more likely in areas exposed to winds.

The reduction in the frequency of large gaps in the older rehabilitating stands suggests that gaps are filled during forest development. Our assessment does not provide information on the species that are filling gaps. This was done by Grainger \& van Aarde (2013) who showed that the species most likely to fill a gap created by $V$. kosiensis was not $V$. kosiensis, but rather other forest pioneers with wide tolerances for light. These 'gap takers' included Mimusops caffra and Celtis africana, broadleaf species that may allow for greater niche space for shade tolerant species to establish in regenerating forest (Grainger \& van Aarde 2013). However, even if these changes in 
composition do occur, the structure of the forest may take a longer time to resemble an undisturbed coastal dune forest. Our results suggest that the frequency of multi-stemmed individuals in rehabilitating forest tended to divert from the endpoint as the forest aged. The increase in multi-stemmed individuals may result from the concurrent effect of a background level of disturbance (i.e. coastal winds and the sandy and unstable soil of dunes) with those resulting from broken and damaged stems when gaps are created. In coastal dune forest, the ability to produce multiple stems is common to most species (Nzunda et al. 2007). These species have higher resprouting rates when part of the stem is still present (Nzunda et al. 2008). Thus, the formation of gaps could, therefore, boost the development of multiple stems in a pool of species where this capacity is widespread. Multi-stemmed can be considered as a mechanism to facilitate persistence following a disturbance. However, the benefits of an increase in survival are accompanied by a reduction in individual height. The allocation of resources to multiple stems can hinder the achievement of the potential height of an individual (Bond \& Midgley 2003). That 'seeders' often grow taller than 'resprouters' is commonly argued as evidence for the trade-off between multi-stemming and maximum height.

When individual heights are lower than expected, it can have profound consequences on the restoration of coastal dune forest. Large trees have been shown to play a key role in tropical forests. They store the vast majority of carbon (Bastin et al. 2015) and provide shelter, nesting sites and multiple resources to different organisms across trophic levels (Lindenmayer et al. 2012). One group benefiting from the presence of large trees are large frugivores, which are of major importance for long distance dispersal and can contribute to restore degraded forest (Galetti et al. 2013). In the studied rehabilitating forest, previous research has shown a decline in large frugivores abundance as the forest age (Rolo et al. 2017). This evidence is in accordance with the significantly lower presence of tall trees in the rehabilitating forest as compared to the reference forest. The recovery of rehabilitating coastal dune forest could, therefore, be delayed, unless the formation of large canopy gaps is minimized.

In conclusion, our results agree with previous research indicating that canopy gaps are an important component of coastal dune forests dynamics (Obiri et al. 2004; Griffiths et al. 2007; Nzunda et al. 2007). Although our results suggest that gaps are filled during forest development, canopy gaps also have the potential to divert regeneration trajectories by affecting individual life-history strategies and morphology. Yet, their effect is partly controlled by exposure to winds (i.e. topographical position). These results have important managerial implications. On one hand, dune slacks could be used as natural loci of plant nucleation. Nucleus are patches of vegetation that have been shown to accelerate recovery by improving seed dispersal and establishment (Zahawi et al. 2013). Applying active nucleation in dune slacks could be a cost effective strategy to improve regeneration trajectories. On the other hand, our results suggest that there is a positive feedback between a disturbance-prone environment, early senescence of fast-growing species and topographic position. Thus, in disturbance-prone environments the use of fast-growing species should be carefully designed to strengthen resilience. 


\section{Acknowledgments}

We thank Glenda Varrie, many research assistants, graduate and post-graduate students who participated in fieldwork over the years. V. Rolo and P. Olivier were supported by a post-doctoral grant from the NRF of South Africa. RJvA was supported by the National Research Foundation (NRF), the Technology and Human Resources for Industry Programme (THRIP) and Richards Bay Minerals who also facilitated our fieldwork.

\section{Author Contributions}

VR designed the methodology, analysed the data and wrote the first version of the manuscript. PO and RA contributed critically to the drafts.

\section{References}

van Aarde, R.J., Ferreira, S.M., \& Kritzinger, J.J. 1996. Successional changes in rehabilitating coastal dune communities in northern KwaZulu/Natal, South Africa. Landscape and Urban Planning 34: 277-286.

van Aarde, R., Guldemond, R.A.R., \& Olivier, P.I. 2014. Biodiversity status of coastal dune forest in South Africa. In Maslo, B. \& Lockwood, J.L. (eds.), Coastal Conservation, Cambridge University Press, Cambridge, UK.

Asner, G.P., Kellner, J.R., Kennedy-Bowdoin, T., Knapp, D.E., Anderson, C., \& Martin, R.E. 2013. Forest canopy gap distributions in the southern Peruvian Amazon. PLOS ONE 8: e60875.

Asner, G.P., \& Warner, A.S. 2003. Canopy shadow in IKONOS satellite observations of tropical forests and savannas. Remote Sensing of Environment 87: 521-533.

Baraloto, C., Herault, B., Paine, C.E.T., Massot, H., Blanc, L., Bonal, D., Molino, J.-F., Nicolini, E.A., \& Sabatier, D. 2012. Contrasting taxonomic and functional responses of a tropical tree community to selective logging. Journal of Applied Ecology 49: 861-870.

Barnes, R.D., Filter, D.., \& Milton, S.J. 1996. Acacia karroo: monograph and annotated bibliography. Oxford Forestry Institute, Department of Plant Sciences, University of Oxford, Oxford, UK.

Bastin, J.-F., Barbier, N., Couteron, P., Adams, B., Shapiro, A., Bogaert, J., \& De Cannière, C. 2014. Aboveground biomass mapping of African forest mosaics using canopy texture analysis: toward a regional approach. Ecological Applications 24: 1984-2001.

Bastin, J.-F., Barbier, N., Réjou-Méchain, M., Fayolle, A., Gourlet-Fleury, S., Maniatis, D., de Haulleville, T., Baya, F., Beeckman, H., Beina, D., (...) \& Bogaert, J. 2015. Seeing Central African forests through their largest trees. Scientific Reports 5: 13156.

Bond, W.J., \& Midgley, J.J. 2003. The evolutionary ecology of sprouting in woody plants. International Journal of Plant Sciences 164: S103-S114.

Brokaw, N.V.L. 1985. Gap-phase regeneration in a tropical forest. Ecology 66: 682-687. 
Brokaw, N.V.L. 1982. The definition of treefall gap and its effect on measures of forest dynamics. Biotropica 14: 158-160.

Burgess, N.D., \& Clarke, G.P. 2000. Coastal Forests of Eastern Africa. IUCN The World Conservation Union, Cambridge, UK.

Chambers, J.Q., Asner, G.P., Morton, D.C., Anderson, L.O., Saatchi, S.S., Espírito-Santo, F.D.B., Palace, M., \& Souza Jr, C. 2007. Regional ecosystem structure and function: ecological insights from remote sensing of tropical forests. Trends in Ecology \& Evolution 22: 414-423.

Chapman, L. 2000. Assessing topographic exposure. Meteorological Applications 7: 335-340.

Coates-Palgrave, K. 2002. Trees of Southern Africa. Struik Publishers, Cape Town.

Denslow, J.S. 1980. Gap partitioning among tropical rainforest trees. Biotropica 12: 47.

Dietze, M.C., \& Clark, J.S. 2008. Changing the gap dynamics paradigm: vegetative regeneration control on forest response to disturbance. Ecological Monographs 78: 331-347.

Dwyer, J.M., Fensham, R., \& Buckley, Y.M. 2010. Restoration thinning accelerates structural development and carbon sequestration in an endangered Australian ecosystem. Journal of Applied Ecology 47: 681-691.

Fahey, R.T., \& Puettmann, K.J. 2007. Ground-layer disturbance and initial conditions influence gap partitioning of understorey vegetation. Journal of Ecology 95: 1098-1109.

Forbes, A. 2017. Canopy manipulations of exotic Bitter Willow (Salix elaeagnos) forest for indigenous seedling recruitment: A pilot study. Ecological Management \& Restoration 18: 78-82.

Forbes, A.S., Norton, D.A., \& Carswell, F.E. 2016. Artificial canopy gaps accelerate restoration within an exotic Pinus radiata plantation. Restoration Ecology 24: 336-345.

Galetti, M., Guevara, R., Côrtes, M.C., Fadini, R., Matter, S.V., Leite, A.B., Labecca, F., Ribeiro, T., Carvalho, (...) \& Jordano, P. 2013. Functional extinction of birds drives rapid evolutionary changes in seed size. Science 340: 1086-1090.

Garbarino, M., Mondino, E.B., Lingua, E., Nagel, T.A., Dukić, V., Govedar, Z., \& Motta, R. 2012. Gap disturbances and regeneration patterns in a Bosnian old-growth forest: a multispectral remote sensing and ground-based approach. Annals of Forest Science 69: 617-625.

Goulamoussène, Y., Bedeau, C., Descroix, L., Linguet, L., \& Hérault, B. 2017. Environmental control of natural gap size distribution in tropical forests. Biogeosciences 14: 353-364.

Gourlay, I.D., Smith, J.P., \& Barnes, R.D. 1996. Wood production in a natural stand of Acacia karroo in Zimbabwe. Forest Ecology and Management 88: 289-295.

Grainger, M.J., \& van Aarde, R.J. 2013. The role of canopy gaps in the regeneration of coastal dune forest. African Journal of Ecology 51: 11-20.

Griffiths, M.E., Lawes, M.J., \& Tsvuura, Z. 2007. Understorey gaps influence regeneration dynamics in subtropical coastal dune forest. Plant Ecology 189: 227-236. 
Hobbs, N.T., \& Hooten, M.B. 2015. Bayesian Models: A Statistical Primer for Ecologists. Princeton University Press.

Jennings, S.B., Brown, N.D., \& Sheil, D. 1999. Assessing forest canopies and understorey illumination: canopy closure, canopy cover and other measures. Forestry 72: 59-74.

King, D.A., Davies, S.J., Tan, S., \& Noor, N.S.M. 2006. The role of wood density and stem support costs in the growth and mortality of tropical trees. Journal of Ecology 94: 670-680.

Lamb, D., Erskine, P.D., \& Parrotta, J.A. 2005. Restoration of degraded tropical forest landscapes. Science 310: 1628-1632.

Lamb, D., \& Gilmour, D.A. 2003. Rehabilitation and Restoration of Degraded Forests. UICN, Gland, Switzerland and Cambridge, UK.

Larson, A.J., Lutz, J.A., Donato, D.C., Freund, J.A., Swanson, M.E., HilleRisLambers, J., Sprugel, D.G., \& Franklin, J.F. 2015. Spatial aspects of tree mortality strongly differ between young and old-growth forests. Ecology 96: 2855-2861.

Liao, J., De Boeck, H.J., Li, Z., \& Nijs, I. 2015. Gap formation following climatic events in spatially structured plant communities. Scientific Reports 5: 11721.

Lindenmayer, D.B., Laurance, W.F., \& Franklin, J.F. 2012. Global Decline in Large old trees. Science 338: 1305-1306.

Malahlela, O., Cho, M.A., \& Mutanga, O. 2014. Mapping canopy gaps in an indigenous subtropical coastal forest using high-resolution WorldView-2 data. International Journal of Remote Sensing 35: 6397-6417.

Mikita, T., \& Balogh, P. 2015. Usage of Geoprocessing Services in Precision Forestry for Wood Volume Calculation and Wind Risk Assessment. Acta Universitatis Agriculturae et Silviculturae Mendelianae Brunensis 63: 793-801.

Mucina, L., Geldenhuys, C.J., \& Rutherford, M.C. 2006. Afrotemperate, subtropical and azonal forests. The vegetation of South Africa, Lesotho and Swaziland. Strelitzia 19: 584-614.

Nzunda, E.F., Griffiths, M.E., \& Lawes, M.J. 2007. Multi-stemmed trees in subtropical coastal dune forest: Survival strategy in response to chronic disturbance. Journal of Vegetation Science 18: 693-700.

Nzunda, E.F., Griffiths, M.E., \& Lawes, M.J. 2008. Sprouting by remobilization of above-ground resources ensures persistence after disturbance of coastal dune forest trees. Functional Ecology 22: 577-582.

Obiri, J.A.F., Lawes, M.J., \& Harcombe, P. 2004. Chance versus determinism in canopy gap regeneration in coastal scarp forest in South Africa. Journal of Vegetation Science 15: 539-547.

Pasanen, H., Rouvinen, S., \& Kouki, J. 2016. Artificial canopy gaps in the restoration of boreal conservation areas: long-term effects on tree seedling establishment in pine-dominated forests. European Journal of Forest Research 135: 697-706. 
Pfeifer, M., Gonsamo, A., Disney, M., Pellikka, P., \& Marchant, R. 2012. Leaf area index for biomes of the Eastern Arc Mountains: Landsat and SPOT observations along precipitation and altitude gradients. Remote Sensing of Environment 118: 103-115.

Pinagé, E.R., Matricardi, E. a. T., Leal, F.A., \& Pedlowski, M.A. 2016. Estimates of selective logging impacts in tropical forest canopy cover using RapidEye imagery and field data. iForest Biogeosciences and Forestry 9: 461.

Pretzsch, H. 2009. Forest Dynamics, Growth, and Yield. Springer, Berlin Heidelberg.

R Core Team. 2017. R: A language and environment for statistical computing. $R$ Foundation for Statistical Computing, Vienna, Austria.

Rolo, V., Olivier, P., \& van Aarde, R. 2016. Seeded pioneer die-offs reduce the functional trait space of new-growth coastal dune forests. Forest Ecology and Management 377: 26-35.

Rolo, V., Olivier, P.I., \& van Aarde, R. 2017. Tree and bird functional groups as indicators of recovery of regenerating subtropical coastal dune forests. Restoration Ecology 25: 788-797.

Schnitzer, S.A., \& Carson, W.P. 2001. Treefall gaps and the maintenance of species fiversity in a tropical Forest. Ecology 82: 913-919.

Sturtz, S., Ligges, U., \& Gelman, A. 2005. R2WinBUGS: A Package for Running WinBUGS from R. Journal of Statistical Software 12: 1-16.

Vleut, I., Levy-Tacher, S.I., de Boer, W.F., Galindo-González, J., \& Ramírez-Marcial, N. 2013. Can a fast-growing early-successional tree (Ochroma pyramidale, Malvaceae) accelerate forest succession? Journal of Tropical Ecology 29: 173-180.

Zahawi, R.A., Holl, K.D., Cole, R.J., \& Reid, J.L. 2013. Testing applied nucleation as a strategy to facilitate tropical forest recovery. Journal of Applied Ecology 50: 88-96.

\section{Appendices}

Appendix S1. Overview of the study area.

Appendix S2. Mixture distribution of canopy openness.

Appendix S3. NDVI values at ten years since rehabilitation. 
Table 1 Canopy gaps attributes for each rehabilitating site and a reference forest.

\begin{tabular}{cccccc}
\hline $\begin{array}{c}\text { Site age, } \\
\text { years }\end{array}$ & $\begin{array}{c}\text { Gap cover } \\
(\%)\end{array}$ & $\begin{array}{c}\text { Gap density } \\
\left(\text { num ha }{ }^{-1}\right)\end{array}$ & $\begin{array}{c}\text { Max gap size } \\
\text { (ha) }\end{array}$ & $\begin{array}{c}\text { Mean gap size } \\
\left(\mathrm{m}^{2} \pm \mathrm{SE}\right)\end{array}$ & $\begin{array}{c}\lambda \text {-value } \\
(95 \% \mathrm{Cl})\end{array}$ \\
\hline Reference & 0.13 & 2.59 & 3.2 & $516.9 \pm 72.1$ & $1.43(1.39,1.47)$ \\
38 & 0.08 & 2.74 & 0.3 & $275.8 \pm 51.3$ & $1.48(1.42,1.56)$ \\
35 & 0.26 & 3.98 & 7.1 & $646.0 \pm 189.7$ & $1.44(1.39,1.47)$ \\
31 & 0.30 & 4.07 & 2.5 & $747.2 \pm 167.4$ & $1.41(1.36,1.48)$ \\
27 & 0.23 & 4.99 & 1.2 & $465.5 \pm 77.0$ & $1.40(1.34,1.44)$ \\
23 & 0.21 & 3.42 & 2.9 & $608.4 \pm 124.7$ & $1.38(1.34,1.43)$ \\
\hline
\end{tabular}

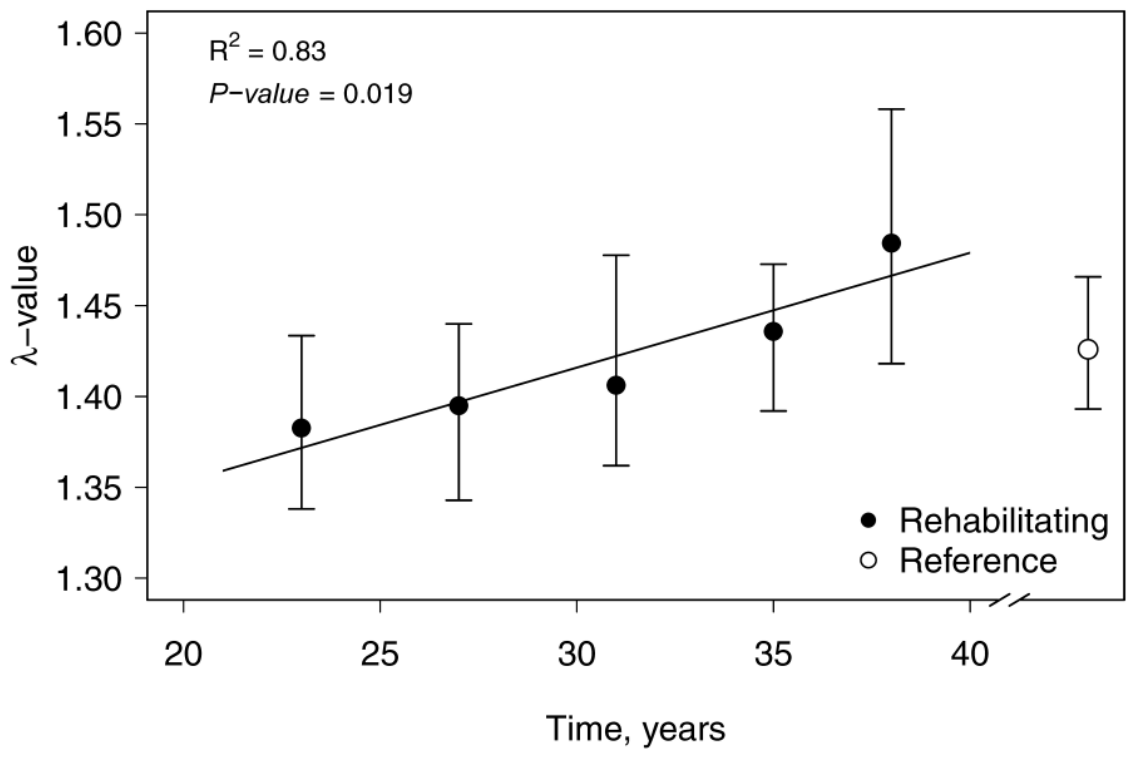

Figure 1. Relationship between power-law exponents ( $\lambda$-values) and time since rehabilitation in rehabilitating and a reference forest. A power-law exponent value of $\sim 2.0$ distinguishes between sites dominated by large $(\lambda$-values $<2.0)$ or small $(\lambda$-values $>2.0)$ gaps. 


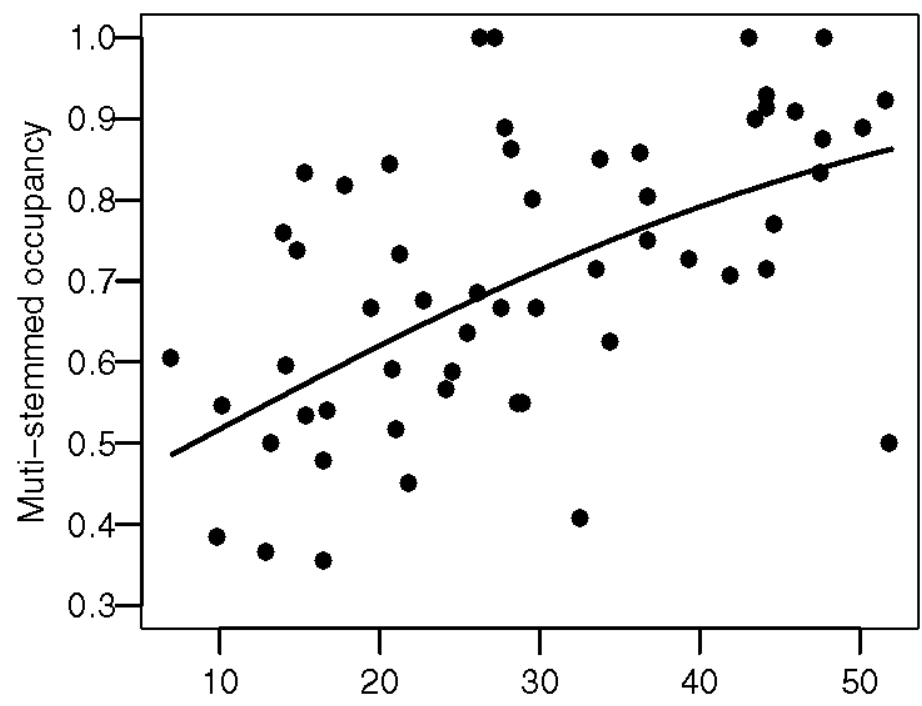

Canopy openness, \%

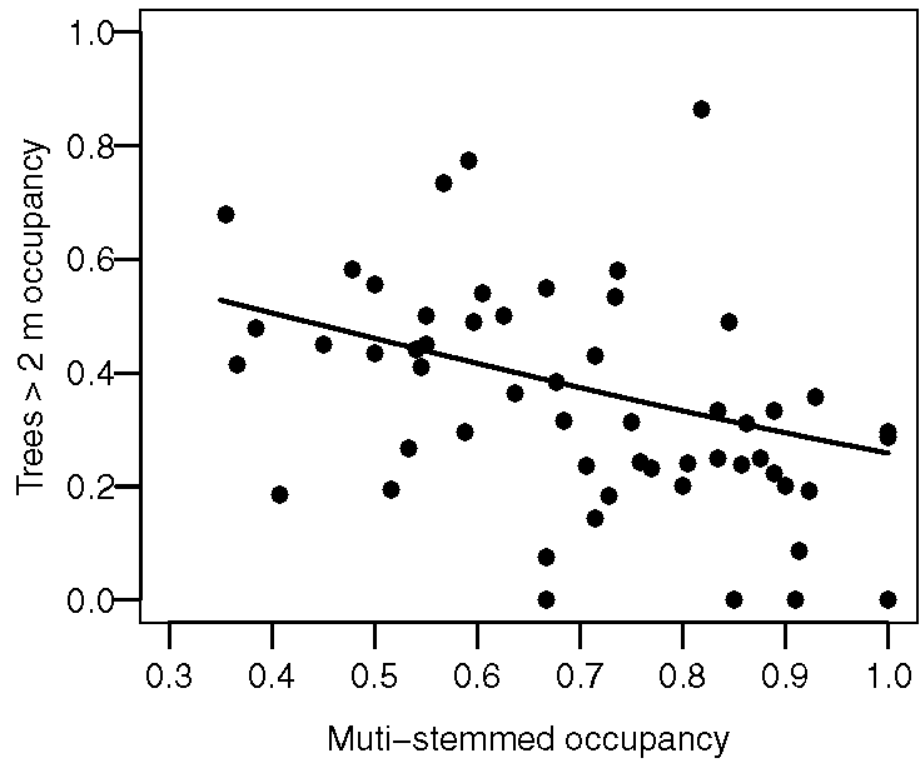

Figure 2. Relationship between canopy openness and the probability of multi-stemmed individual presence species (top) and between multi-stemmed individual presence and maximum height (bottom). 

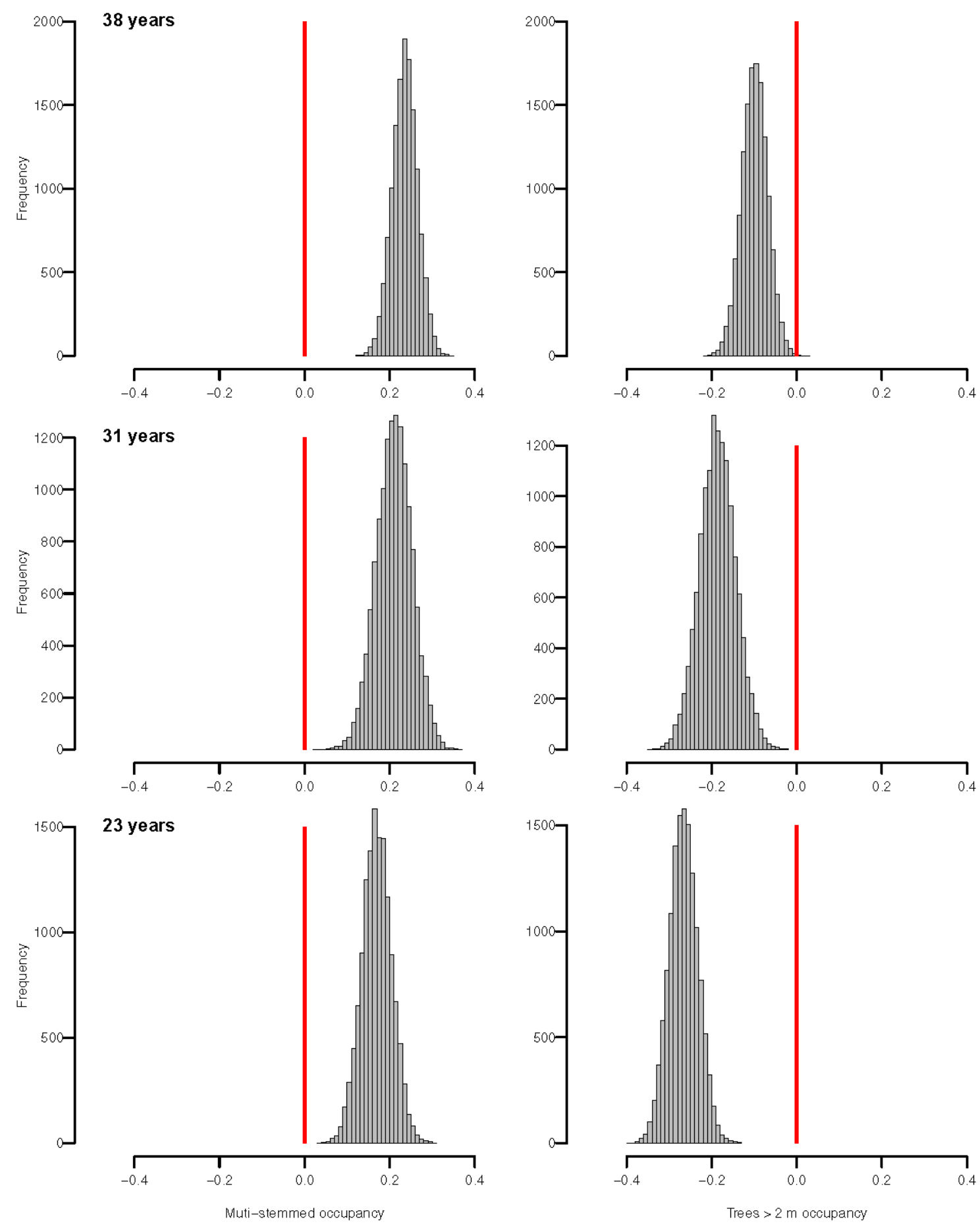

Figure 3. Posterior distribution of the difference between rehabilitating sites and the reference forest of the presence of multi-stemmed individuals (left column) and individuals higher than $2 \mathrm{~m}$ (right column) 